\title{
Novela policiaca y hermenéutica: el colapso de la argumentación del detective como metáfora epistémica de Blanco nocturno
}

\author{
Enrique FERRARI NIETO \\ Universidad de Extremadura \\ ¿Qué es una novela policiaca? Un intento de organizar el caos. \\ Por eso mi Cosmos, que me gusta llamar "una novela sobre \\ la formación de la realidad", será una especie de novela policial. \\ Witold Gombrowicz, Cosmos
}

\begin{abstract}
RESUMEN
Al tiempo que en la filosofía se extiende la desconfianza en el método analítico, surge con fuerza la novela policiaca, con su estructura lógica, deductiva, que fía los resultados al rigor de su metodología. Ricardo Piglia, con Blanco nocturno (2010), una novela policiaca vuelta del revés, cuestiona el artificio de este género para reflexionar, en un ejercicio metaliterario que queda superpuesto a la trama, sobre las claves de la interpretación. Sugiere una hermenéutica, sacada de la propia novela, que reclama otros mecanismos para la comprensión, despreciados por el razonamiento analítico, como la analogía, muy cerca de otras propuestas filosóficas contemporáneas.
\end{abstract}

Palabras clave: metaliteratura, interpretación, Gombrowicz, Sabato, Bolaño.

Whodunit and hermeneutics: the collapse of the detective's argument as epistemic metaphor of Blanco nocturno

\begin{abstract}
When philosophy begins discarding the analytical method, the whodunit appears strongly, with a deductive structure that trusts the results to the rigor of its methodology. Ricardo Piglia -with Blanco nocturno (2010), a detective story turned inside out- doubts the literary artifice of the genre. He reflects on the interpretation, in an exercise metaliterary. He suggests a hermeneutic for the understanding, with other mechanisms that have been neglected by analytical reasoning. For example: the analogy. Close to other contemporary philosophical proposals.
\end{abstract}

Key words: Metaliterature, Interpretation, Gombrowicz, Sabato, Bolaño.

SUMARIO: 1. La novela como interpretación. 2. Cosmos, de Gombrowicz: el colapso de la deducción lógica. 3. La desconfianza en el método, envés de la novela policiaca. 4. Sobre el objeto y modos de la novela: Ernesto Sabato y Roberto Bolaño. 5. Blanco nocturno como ficción paranoica. 
Escribe Joseph Margolis, imbricados en su filosofía el historicismo y el constructivismo, que hemos agotado cualquier argumento sobre nuestros privilegios cognitivos (1999: 41-66), que no podemos agarrarnos todavía, con esa confianza cándida del pasado, a una realidad estable y objetiva que vamos rascando -o, con ese otro verbo de la etimología griega para la verdad, desvelando- con nuestro conocimiento. Toda ciencia es una ciencia humana, dice. Con lo que entonces solo queda la interpretación. Lo que vio ya Nietzsche, que hizo de la hermenéutica la pieza clave de la filosofía: no hay hechos, decía, sino interpretaciones. Una brecha abierta, una posición de resistencia a los cantos de sirena analíticos, que se ha ido fortaleciendo en su recorrido de más de un siglo, también en la cuna del pensamiento occidental, con esa sospecha o desconfianza por los temas y métodos anteriores. Con la objeción, por ejemplo, de María Zambrano: "O sobra de arquitectura, de supuestos, o falta de firmeza y de última claridad en lo aprehendido. La mariposa, en unos casos se muere, en otros se escapa" (2000: 29). Comprender, interpretar, no es solo una instancia científica, escribe Gadamer, sino que pertenece a la experiencia humana del mundo. No puede reducirse, en principio, a un problema metódico (2001: 23). Porque no hay una filosofía inocente, escribe Emilio Lledó (1999: 91). Discurrir, discurso, o investigar, dice, son metáforas, aunque muy gastadas ya, que remiten a caminar, a dar con algo en el camino (Lledó 1999: 51): implícitos el movimiento y las alternativas, frente al objeto estático con el que parece identificarse a veces (intuitivamente) a la verdad. El propio texto -textum en latín- significa tejido, urdimbre de distintos hilos.

En esta misma brecha abierta Ricardo Piglia busca su espacio. Su reflexión metaliteraria, soportada en la trama de un crimen en Blanco nocturno, es un planteamiento teórico sólido sobre la propia interpretación: sobre la búsqueda de un sentido que se sonsaca a sí misma (o de sí misma), como novela, como artefacto, con la defensa valiente y honesta de su comisario Croce de la analogía como el mecanismo propio del pensamiento: una alternativa al método analítico de la novela policiaca clásica que lo coloca en un plano distinto, menos ingenuo, más cerca de las preocupaciones actuales de la filosofía que del género, que sigue aún recreándose en su propia estructura.

\section{La novela como interpretación}

Al mirarse por dentro, cualquier hermenéutica empieza por justificarse sus límites, qué acepta y qué no acepta para la interpretación, qué puede permitirse el método que propone y qué no. Comprender es el modo de ser del propio estar ahí, dice Gadamer (2001: 12): un comportamiento intuitivo, muy básico (Gadamer 2001: 23); pero, como disciplina rigurosa, necesita una justificación de sí misma (fuera del campo de atracción de la ciencia, del método científico) que, en su propia introspección, puede acabar por imponerle una gravedad que la vuelva demasiado recatada, demasiado precavida: reforzándola como metodología por ese rigor suyo en el derecho de admisión; pero desestimando también algunas propuestas, algunas 
intuiciones, porque el camino con el que llega a ellas o con el que las ensarta no parezca el más pertinente. Al exigirse a sí misma, como teoría, acreditar cada aportación, muchas tienen que quedar en el aire, fuera, a pesar de su interés, de su valor, en la reflexión vastísima que cabe detrás de la interpretación: con tantos frentes. Es lo más sensato: la hermenéutica, como filosofía, como epistemología, atenta sobre todo al método, tiene que ser concienzudamente cauta con la articulación de sus propuestas. Pero la novela puede arriesgar más: es más atrevida, más descarada también, porque el desorden de sus planteamientos no repercute sobre ella, no la deslegitima, y muchas veces atina, dando en el punto exacto, aunque quede todo en el aire, sin el trabajo de albañilería que supone crearle a la intuición literaria una construcción sistemática.

Ricardo Piglia, en su Blanco nocturno, de 2010, superpone a la trama unas pautas sobre la interpretación, para una hermenéutica que quiere ser más laxa, más tolerante, sin tantos vetos. Le da la vuelta a la novela policiaca: En Blanco nocturno hay un crimen y una primera resolución que se atiene al método, o mejor: a las evidencias, como en otra novela cualquiera, pero que está equivocada; y una segunda resolución, del comisario Croce, que arranca de una intuición, sin un razonamiento que justifique el punto de partida, pero que acierta con las causas. La novela policiaca se recrea en su método analítico, en ir reconstruyendo un argumento lógico, en ir dando los mismos pasos que el criminal, segura de acabar en la misma meta: desde sus inicios, desde que Auguste Dupin, en Los crímenes de la calle Morgue que publica Poe en 1841, establece sus dos postulados para resolver un crimen: fundamentarse en deducciones y no adivinar nada. Como una máquina lógica perfecta. La novela de Piglia, en cambio, le busca recovecos al análisis: A la matemática, como dice el propio Croce, le suma la poesía. Con la misma legitimidad, porque le viene dada por el resultado, por su acierto, aunque su método sea casi el contrario: no solo la razón; también la inspiración espontánea. Como si buscara minar la confianza en un razonamiento tan seguro de sí mismo como este de las reconstrucciones detectivescas. Con una alternativa que es eficaz pero injustificable: con las deducciones de Croce, con sus modos de hacer comprensible cada crimen, que parecen saltos al vacío. ${ }^{1}$ Como si con el molde de la novela policiaca, con las simetrías que genera el método, Piglia quisiera llevar sus pautas a la órbita de la hermenéutica, con su sugerencia sobre la diversidad de

\footnotetext{
${ }^{1}$ Basta un solo ejemplo: “Acertó muchas veces porque parecía ver cosas que el resto de los mortales no podía ver. Por ejemplo, acusó a un hombre de haber violado a una muchacha porque lo vio salir dos veces del cine donde daban Dios se lo pague. Y el hombre realmente la había violado aunque el dato que lo llevó a incriminarlo no parecía tener sentido. Otra vez descubrió a un cuatrero porque lo vio tomar el tren a la madrugada para ir a Bolívar. Y si va a Bolívar es porque quiere vender la hacienda robada, dijo. Dicho y hecho.” (Piglia 2010: 27)
} 
significados, de interpretaciones. Como si pretendiera dilatarla, estirar sus márgenes, más permisiva, al denunciar las estrecheces de un método demasiado mecánico, demasiado lógico, que se deja fuera instrumentos básicos. Uno de ellos, fundamental, dice, para poder ir ampliando lo que conocemos: La analogía. Con ese alegato tremendo del comisario, casi fundacional: "Se trata -dijo-, claro, de una metáfora, de un símil, pero también de una verdad literal. Porque nosotros trabajamos con metáforas y con analogías, con el concepto de igual a, con los mundos posibles, buscamos la igualdad en la diferencia absoluta de lo real. Un orden discontinuo, una forma perfecta. El conocimiento no es el develamiento de una esencia oculta sino un enlace, una relación, un parecido entre objetos visibles. Por eso -y usó nuevamente la primera persona del singular- solo puedo expresarme con metáforas" (2010: 243). Cerca, en la tradición filosófica, de los pitágoricos, de Platón, de Aristóteles, de Tomás de Aquino, de Suárez, Hume, Leibniz, Kant, de otros muchos. ${ }^{2}$ Como si Piglia, al colapsar la novela policiaca, intentara un nuevo acuerdo de mínimos para la comprensión tras el descreimiento de una sola posible lectura, de la infalibilidad de la lógica, del razonamiento analítico. Menos ingenuo, pero no resignado: buscándole alternativas. Convencido de que en la novela pueden expresarse también pensamientos, aunque de otro modo que en filosofía. ${ }^{3}$

\section{Cosmos, de Gombrowicz: el colapso de la deducción lógica}

En la construcción de una novela (de una novela ambiciosa al menos) es inevitable también una reflexión sobre sí misma. En su propia construcción incluye, como puntales, elementos metaliterarios; pero fundidos con los demás, como advierte el narrador de "El arte narrativo y la magia" de Borges: esa casi inextricable complejidad de los artificios novelescos que es laborioso desprender de la trama (2008: I, 263). Aunque permiten luego, en la reconstrucción que es la lectura y el análisis de la obra, varios niveles. Este que reflexiona sobre la propia novela, por lo general más oculto, detrás de la trama, alimentándose de ella pero, al tiempo, apuntalándola con la reflexión teórica, dándole una dimensión más honda, interconectando la realidad que intenta plasmar la ficción -un ejercicio que puede parecer más ingenuo- ${ }^{4}$ con los mecanismos expuestos de la propia ficción: Un

${ }^{2}$ Escribe Luis Álvarez Colín: "La analogía recorre el pensamiento filosófico y como instrumento de descubrimiento, de identificación y de síntesis nos permite superar los límites actuales de la experiencia humana y del conocimiento." (2004: 5-26)

${ }^{3}$ Escribe Piglia sobre Macedonio: "Le parece posible que en una novela puedan expresarse pensamientos tan difíciles y de forma tan abstracta como en una obra filosófica, pero a condición de que parezcan falsos. 'Esta ilusión de falsedad', dijo Renzi, 'es la literatura misma' [...] Ese 'todavía no', dice Renzi, es la literatura misma." (Piglia 2000: 28 y 83-84)

${ }^{4}$ Sobre la historia que cuenta una novela: Cf. Forster 1990: 31-48. 
engarce, un punto de encuentro, que en unos pocos casos excepcionales es una metáfora inmensa que a un tiempo acoge a la ficción, como horma de la trama, y es la clave de su propia interpretación, como reflexión de la literatura.

El sustrato inmediato que hay bajo el terreno que pisa Piglia es Gombrowicz; o mejor, es el erial que deja Gombrowicz el piso que Piglia intenta trabajar: Para Eco la misión del arte ha consistido (hasta hace poco) en ordenar el caos, en cerrar una parcela de la realidad para dominarla, para ponerle unas leyes estrictas que E.M. Forster cimienta en la causalidad en el argumento (1990: 92). Gombrowicz, con Cosmos, demuestra la ingenuidad de esa pretensión, ${ }^{5}$ los abusos que puede generar esa búsqueda de una legislación propia demasiado rigurosa, demasiado imperiosa. Apunta toda la escena, que luego recogerá Piglia. En Cosmos, en 1967, lleva al absurdo la aspiración del narrador de querer una síntesis capaz de explicarlo todo. Toma dos elementos, un pájaro ahorcado y las bocas de unas chicas, y pretende relacionarlos, ordenarlos, implicándolos en una relación causal demente, pero que entiende que debe existir, forzando al máximo una deducción que salta por los aires cuando continúa con la síntesis incorporándole nuevos elementos, algunos motivados por él mismo, para dar con la secuencia lógica de ahorcamientos y bocas. Hace de Cosmos el intento paranoico de explicar cómo ha aparecido un pájaro ahorcado: "algo absurdo", dice, al que intenta asociarle otros elementos para dar con una explicación global: para hacer de un "cadáver absurdo" un "cadáver lógico". Le asocia bocas y ahorcamientos, casualidades a las que intenta atar con una lógica, forzando las relaciones, incluso llevando a cabo él los hechos que faltan para construir la secuencia, hasta colgar a Lena, después de haber colgado a su gato, y de haberse colgado Ludwik.

Gombrowicz arrasa con la novela policiaca clásica: Unos escombros de los que Piglia saca una reflexión global sobre la interpretación. De algún modo lo que ha hecho antes Cervantes con los libros de caballería: Darles la vuelta. Que en Piglia, en su reflexión sobre los métodos de la interpretación en este erial con que se encuentra, es incorporar la poesía a estos ejercicios de comprensión (de investigación), para salvarlos, para hacerlos viables, como mecanismo complementario. A partir de una trama policiaca: el paradigma de la deducción lógica en literatura. Que él vuelve problemática, aprovechándose de ese privilegio que se le concede al detective de ver de forma distinta, al cuestionar sus propios fundamentos, al darle legitimidad a una vía que esta ha descartado para el método, una alternativa que queda avalada por los buenos resultados de Croce: también con la asociación libre, muchas veces con la analogía: de la certeza de Descartes a los

${ }^{5}$ Lo que señala también el narrador de Los sinsabores del verdadero policía de Amalfitano: "Comprendió algo que en el fondo sabía desde siempre: que el Todo es imposible, que el conocimiento es una forma de clasificar fragmentos.” (Bolaño 2011: 259) 
alfileres con los que Croce tiene armada su investigación. Escribe: "Hay que saber pensar como piensa el enemigo -dijo de pronto-. Actúa como un matemático y un poeta. Sigue una línea lógica pero al mismo tiempo asocia libremente. Construye silogismos y metáforas. Un mismo elemento entra en dos sistemas de pensamiento. Estamos frente a una inteligencia que no admite ningún límite. Lo que en un caso es un símil, en el otro es una equivalencia. La comprensión de un hecho consiste en la posibilidad de ver relaciones. Nada vale por sí mismo, todo vale en relación con otra ecuación que no conocemos" (Piglia 2010: 265). Lo que puede servirnos -echo mano de nuevo a Eco- como metáfora epistemológica de la incertidumbre de nuestro tiempo, de la desconfianza ante lo que, hasta hace muy poco, parecía tan sólido (Eco 1984: 78-79).

\section{La desconfianza en el método, envés de la novela policiaca}

Para la escritura Roberto Bolaño tiene una definición rotunda, que toma de un verso de Nicanor Parra: Es, dice, como ordeñar una vaca para tirarle luego la leche a la cara (Bolaño 2003a: 137). Bolaño, con una vida de perros, tremendamente precaria, miserable, quiso una literatura valiente, capaz de arriesgar en la búsqueda para sonsacarle unas pocas respuestas a la realidad o a la vida o a sí mismo. Con esas dos acciones: audaz en la indagación, pero audaz también en la presentación de lo encontrado: escéptico, nada rimbombante, pero satisfecho por la honestidad con que podía presentar los resultados, con al menos unas cuantas de sus novelas, excepcionales, y también con una reflexión persistente, una poética hecha con pasos muy cortos, con las vueltas que da a esa impresión de una búsqueda fatigosa para la literatura. Que pensara, con Parra, en una vaca para la analogía tuvo que ser por ese gusto suyo por la provocación; pero también por su rechazo a los lugares comunes y a las sentencias huecas pero arrogantes, muchas veces en seguida consolidadas, admitidas por todos, o la mayoría, que prefieren fiarse antes que andarle a la narrativa con los correajes para sacarle de dentro las respuestas. Bolaño usa el desierto como espacio para esas respuestas: una metáfora muy visual para la búsqueda durísima, y peligrosa, que es la literatura. Para él con una ambición epistémica clara: Una perspectiva fundamental para la filología o la estética, pero difícil de explicar, porque la literatura no es sistemática, ni analítica, ni lógica, ni puede presentar ventajas evidentes, suficientemente convincentes, frente a otras disciplinas, como la ciencia o incluso la filosofía, a pesar de los alegatos del romanticismo: Los distintos argumentos que han defendido la capacidad única de la novela para dar un conocimiento son más bien intuiciones, divagaciones. Sobre todo de novelistas, en un ejercicio crítico, de reflexión, sobre su propio trabajo; no una propuesta en firme, redonda, sin tantas aristas. Como si fueran detectives amateurs, emulando a Dupin, a Sherlock Holmes, a Marlowe, a tantos otros, intentando imitar su método resultón, la perspicacia del análisis y la deducción, pero con los pasos más torpes, porque son a la fuerza más desconfiados, porque saben que no les sirve el alivio final con el que la novela policiaca tranquiliza al 
lector. Miran de reojo porque lo suyo es también una búsqueda, un ejercicio epistémico, de sonsacar o intentar sonsacar un conocimiento, porque se saben de algún modo también detectives (esa imagen de sí mismos les gusta), pero son menos ingenuos, quizá porque cualquier resolución suya no puede alejar del todo las dudas, porque la construcción del sentido que es la lectura o la escritura deja siempre vivas, como posibles, otras propuestas.

Con Croce, su protagonista en Blanco nocturno, Piglia se planta ante la filosofía, ante los modos prestigiados del pensamiento, ante el método, que tuvo con Hegel su apoteosis. Dentro de su coche, de noche, mientras espera, piensa el comisario: "El búho de Minerva también se confunde y se pierde" (Piglia 2010: 97). Casi en un delirio. Como si le llegaran las palabras en vez de fabricarlas él, para agrandar esa brecha mínima que abre Hegel, para incidir más en las limitaciones de ese emblema que el filósofo alemán hace suyo de la diosa de la sabiduría para advertir que la filosofía llega tarde para enseñar cómo debe ser el mundo: "el búho de Minerva sólo levanta su vuelo al romper el crepúsculo", escribe este (Hegel 1993: 61). ${ }^{6}$ Un escepticismo, con sus alternativas para descubrir el crimen, que le sirve al narrador (en su meditación, más abarcadora) para intentar hacer el recorrido inverso, para volver al inicio, también con las vías muertas, desacreditadas, en un espacio mucho más ancho que el corredor que emplea el método científico, sistemático. Un buen punto de partida para una reflexión en torno a las posibilidades de la interpretación, como un preámbulo para la hermenéutica, con el que volver a plantear la desconfianza en el método, para calibrarla: aquí a partir de la literatura, de la novela, a un tiempo objeto y soporte de la investigación de Ricardo Piglia, que con Blanco nocturno se atreve con una reflexión metaliteraria que va construyendo al tiempo que narra las investigaciones del comisario Croce. Como si quisiera mostrar, en otro nivel, pero comunicado siempre con la trama policiaca de la novela, sus reparos con el método, con la capacidad del análisis del policía o el detective para dar con las respuestas, que es también la de cualquier búsqueda: Un detective es (o debe ser) analítico, intelectual, lógico. De su comisario Croce escribe al principio: "Tenía una intuición tan extraordinaria que parecía un acto de adivinación." "Un poco tocado": "Como quien oye una música y no puede sacarla en el piano: un hombre

${ }^{6}$ La cita entera: "Por lo demás, para decir aún una palabra sobre su pretensión de enseñar cómo debe ser el mundo, la filosofía llega siempre demasiado tarde. Como pensamiento del mundo sólo aparece en el tiempo después de que la realidad ha cumplido su proceso de formación y se ha terminado. Lo que enseña el concepto lo muestra necesariamente igual la historia, de modo que sólo en la madurez de la realidad aparece lo ideal frente a lo real y se hace cargo de este mundo mismo en su sustancia, erigido en la figura de un reino intelectual. Cuando la filosofía pinta su gris sobre gris, entonces ha envejecido una figura de la vida y, con gris sobre gris, no se deja rejuvenecer, sino sólo conocer; el búho de Minerva sólo levanta su vuelo al romper el crepúsculo." 
imprevisible que deliraba un poco y no tenía reglas pero siempre acertaba y era ecuánime" (Piglia 2010: 26-27). Para colocarse él en tierra de nadie, en ese erial, en ese escenario destartalado. Incrédulo. Como el dentista que no consigue sacar una muela porque se le resbalan las tijeras (Gombrowicz 1982: 179). Pero sopesando alternativas. Tanteando nuevos espacios para la interpretación, porque sabe, con Gadamer, que ver es siempre una lectura articulada de lo que hay (Gadamer 2001: 131). Escribe más adelante: "Según el fiscal, Croce era un anacronismo. Cueto quería modernizar a la policía y trataba a Croce como si fuera un policía rural, un sargento a cargo de la partida. Tenía razón. El problema era que Croce resolvía todos los casos" (Piglia 2010: 108).

Piglia, que es un crítico excepcional, un gran lector, también de literatura policiaca (dirigió la Serie Negra), construye su respuesta a un tiempo con la trama criminal y con la reflexión metaliteraria, una y otra como si fueran isomorfas en su alegato a favor de otras formas que no son las analíticas, como una aportación más a ese diálogo que recorre la literatura contemporánea, en torno a la fiabilidad de las respuestas de cualquier construcción interpretativa demasiado pretenciosa. Como si Piglia buscara con Blanco nocturno ese parentesco con Gombrowicz pero, a la vez, un ejercicio de contención de sus tesis: como si estuviera de su lado, pero sujetándolo, añadiéndole a su delirante Cosmos, para poder salir de ahí, una alternativa o, al menos, una resignación más sosegada, para evitar un equivocismo total, o para evitar darle legitimidad a un equivocismo total: Le dice Croce a Renzi: "Vos leés demasiadas novelas policiales, pibe, si supieras cómo son verdaderamente las cosas... No es cierto que se pueda restablecer el orden, no es cierto que el crimen siempre se resuelve... No hay ninguna lógica. Luchamos para restablecer las causas y deducir los efectos, pero nunca podemos conocer la red completa de las intrigas... Aislamos datos, nos detenemos en algunas escenas, interrogamos a varios testigos y avanzamos a ciegas. Cuanto más cerca estás del centro, más te enredas en una telaraña que no tiene fin. Las novelas policiales resuelven con elegancia o con brutalidad los crímenes para que los lectores se queden tranquilos" (Piglia 2010: 283). Con los dos planos: la literatura y la realidad, que se miran recíprocamente en toda la novela, en esta vuelta que le da Piglia a la novela policiaca, al hacer saltar por los aires la confianza del detective o el policía por el método, por la resolución puramente intelectual. Con muchas referencias elididas del lado de la literatura, sobre esa disposición con la que la literatura ordena sus elementos para poderse hacer con ellos. Un diálogo al que Piglia le ha debido de poner muchas voces, para ese trabajo ingente que es minar una confianza muy afianzada. Pero que para verle la estela basta con apuntalar con unos pocos autores, de tantos posibles, porque, en alguna medida, toda novela es policiaca -un puzzle, dice Bolaño (2008: 161)-, en todas hay un patrón de búsqueda.

Indico rápidamente dos (también contemporáneas, también en español), que han sabido acertar con un símbolo inagotable: Sobre héroes y tumbas (1961), de Sabato, y Los detectives salvajes (1998) del propio Bolaño: ambas sobre las posibilidades 
epistémicas de la novela: sobre su tema y su recorrido o su acceso: Ernesto Sabato, con una analogía, señala el tema de la literatura: el mal, que representa con los ciegos: un primer punto. Roberto Bolaño, con una analogía, señala el camino inclemente de la búsqueda: el desierto: un segundo punto. También con una analogía Ricardo Piglia señala ahora las dudas sobre el resultado: con el comandante Croce, un viejo policía que desconfía de las razones para cerrar un caso: el último punto; esa misma vuelta a la novela policiaca que hizo antes Witold Gombrowicz, pero más comedida, más equilibrada, porque le encuentra, como digo, una vía de escape, cerca de la hermenéutica. Como si se propusiera avanzar un poco más que su precursor, pero con esa misma hoja de ruta que deja registrada Gombrowicz también en su diario, en 1963: "Trazo dos puntos de partida, dos anomalías muy distantes una de otra: a) un gorrión colgado; b) la asociación entre la boca de Katasia y la boca de Lena. Estos dos problemas exigen un sentido. E1 uno penetra en el otro tendiendo hacia la totalidad. De este modo comienza un proceso de suposiciones, de asociaciones, de investigaciones, algo que va a crearse, pero se trata de un embrión más bien monstruoso, un aborto... y este rebus oscuro, incomprensible, exigirá una solución... buscar una Idea que explique, que imponga un orden..." (Gombrowicz 1982: 7).

\section{Sobre el objeto y modos de la novela: Ernesto Sabato y Roberto Bolaño}

Roberto Bolaño se maneja siempre con dos imágenes: la del detective (o el policía) y la del desierto, tanto para la escritura como para la lectura, que entiende como búsqueda, como un mecanismo único capaz de rascar en el hombre o en su realidad. El detective es el que investiga, el que mete la cabeza en lo oscuro, dice; nada que ver con una actitud naïf, ni tampoco solo lúdica. Quiere poner en un primer plano las condiciones de la búsqueda: lo que se está jugando el que escribe o el que lee: el riesgo y las condiciones lastimosas que son necesarios para dar con ese conocimiento que crea o recrea la ficción. ${ }^{7}$ El desierto de Sonora, al norte de México, es el escenario en el que acaban casi todos sus personajes, o bien porque huyen o bien porque buscan a los que han huido: A Cesárea Tinajero la buscan los detectives salvajes, a los detectives salvajes los buscan el proxeneta y el policía, y a Archimboldi (que va a México en busca de su sobrino) lo buscan los filólogos europeos. El desierto es en Bolaño el punto final: el destino último del personaje enigmático, de Cesárea Tinajero en Los detectives salvajes o de Archimboldi en 2666, y, por tanto, la referencia para las distintas búsquedas de los realvisceralistas y los filólogos europeos. En el desierto de Sonora converge su narrativa, con su propuesta de asomarse al abismo, porque el abismo es el desierto, con esa

${ }^{7}$ Escribe Madero, narrador de Los detectives salvajes: "La literatura no es inocente, eso lo sé yo desde que tenía quince años.” (Bolaño 2003b: 151) 
evocación del desierto de la Biblia: una analogía primero de la literatura y luego de la realidad o la existencia. Para representar una búsqueda ardua, difícil, incómoda, en los libros y en la vida: como el lugar inhóspito, no civilizado, pobre, austero, donde el hombre experimenta su propia vulnerabilidad; $y$, desde ella, la tentación, como un combate espiritual con el mismo demonio, como la prueba más dura, pero por ello también un lugar de encuentro con lo absoluto. En el desierto mexicano, en el punto de intersección en el que se cruzan sus dos grandes novelas, está su gran metáfora: En Lalo Cura, el policía de Santa Teresa que quiere saber (de verdad) qué hay detrás de los crímenes de mujeres, convergen las dos novelas: porque Lalo Cura es -la convergencia exacta, brillante, de las dos novelas (Bolaño 2004: 697)- hijo de los detectives salvajes, de Ulises Lima y de Arturo Belano. Con lo que pone en claro el isomorfismo entre la literatura y la vida, en la búsqueda de respuestas, en los pasos dados hacia lo desconocido. Lo mismo Lalo Cura, que busca en el barranco de Podestá más cadáveres, más pistas, para dar con una respuesta a la que los demás ya han renunciado: en los crímenes está el secreto del mundo, dice. Que las grandes novelas a las que se refiere Amalfitano: "Las grandes obras imperfectas, torrenciales, las que abren camino en lo desconocido [...] Los combates de verdad, en donde los grandes maestros luchan contra aquello, ese aquello que nos atemoriza a todos, ese aquello que acoquina y encacha, y hay sangre y heridos mortales y fetidez" (Bolaño 2004: 289-290).

La misma tesis de Sabato, que en Sobre héroes y tumbas plantea la historia de Alejandra a partir de sus encuentros con Martín, a partir de lo que este va conociendo de ella: una trama existencialista, como la de El túnel, sobre la incomunicación, pero que conduce también a una reflexión metaliteraria, como si fuera su marco. Porque la incapacidad de conocer a Alejandra, con su personalidad tan compleja, con ese pasado tan oscuro, es el punto de partida de la reflexión sobre el poder de penetración de la novela: es el cauce para mostrar las graves limitaciones de la razón pura (que usa otros medios) para conocer al ser humano; también el papel de la novela para suplir esas carencias de lo meramente racional. El "Informe sobre ciegos", la tercera parte del libro, que se ha leído a menudo como un fragmento autónomo, casi como una novela corta independiente de la historia de Martín y Alejandra, es en realidad la pieza central de Sobre héroes y tumbas, porque los ciegos que estudia en su informe Fernando Vidal, padre de Alejandra, es la imagen del mal, de lo irracional, de lo que es humano pero queda fuera de lo racional; lo que en el plano epistémico solo conoce la novela: los rasgos del comportamiento de Alejandra que no puede llegar a entender Martín, pero sí el lector que, con el libro en las manos, completa la escena que le sugiere a Martín el incesto entre padre e hija. A esa primera obsesión por comunicarse, por encontrar en el otro una verdadera comunión, que constituye el argumento existencialista, aquí Sabato incorpora una trama perpendicular para crear dos ámbitos desde los que testar las posibilidades del conocimiento: ese primero de la conversación, con el que Martín no puede ni siquiera entrever el problema, y uno segundo, que abre el 
informe mismo, capaz de penetrar en los ciegos, símbolo del mal y, con una metonimia descorazonadora, del ser humano, que resuelve la novela, despejando las dudas de la reflexión de Bruno, porque en un segundo nivel en la ficción, como obra literaria en la realidad de la ficción, explica la existencia de Alejandra, se adentra en ella y muestra al lector lo que en el primer nivel, en la realidad de la ficción, ha sido imposible desentrañar (Cf. Ferrari 2011: 290-300).

\section{Blanco nocturno como ficción paranoica}

Piglia aprieta la trama de Blanco nocturno: Tony Durán, un puertorriqueño criado en Nueva Jersey, aparece muerto en su habitación, en el hotel en que se hospeda desde que llegó al pueblo, en la provincia de Buenos Aires. Se sospecha de un robo. Pero su dinero, muchos dólares, está junto al cadáver. El comisario Croce se encarga de la investigación. Algunos testigos señalan al conserje del hotel, Yoshio, un japonés, con el que Durán tenía una buena relación. Se declara inocente, pero es detenido. En el pueblo empiezan a circular distintas versiones de lo ocurrido. Se piensa en las gemelas Belladona, en Ada y Sofía, con las que él mantenía un juego a tres bandas. Son las hijas del viejo Belladona, para el que Tony traía los dólares: un modo de ingresar divisas de modo ilegal: la última posibilidad de salvar la fábrica que ahora lleva Luca. Croce cree en la inocencia de Yoshio y busca otro culpable; pero el fiscal Cueto no quiere desprenderse de su único acusado y lo lleva a juicio. Croce insiste en su versión de los hechos: da con el asesino, un jockey que necesitaba el dinero para quedarse con su caballo, pero este ya se ha suicidado, con una nota explicando los hechos. Cueto mantiene la culpabilidad del conserje japonés. Croce es cesado e internado en un psiquiátrico. Cueto le tiende una trampa a Luca Belladona: le llama para testificar en el juicio: si dice que Yoshio es inocente, perderá el dinero y la fábrica; si lo acusa, el dinero será suyo. Luca opta por salvar su fábrica y Yoshio va a la cárcel. Cualquier otra novela policiaca habría terminado bien, habría restituido el orden con su reconstrucción lógica del crimen, cerrando el caso, para tranquilizar al lector (Cf. Echaburu 2006: 7). Esta no. Quiere ir más allá, cuestionarse a sí misma, sin el artificio con que se cierran otras: "Mientras Croce siga en pie, Cueto nunca va a estar tranquilo, pensó Renzi mientras bajaba a la calle. La historia sigue, puede seguir, hay varias conjeturas posibles, queda abierta, solo se interrumpe. La investigación no tiene fin, no puede terminar. Habría que inventar un nuevo género policial, la ficción paranoica. Todos son sospechosos, todos se sienten perseguidos. El criminal ya no es un individuo aislado, sino una gavilla que tiene el poder absoluto. Nadie comprende lo que está pasando; las pistas y los testimonios son contradictorios y mantienen las sospechas en el aire, como si cambiaran con cada interpretación. La víctima es el protagonista y el centro de la intriga; no ya el detective a sueldo o el asesino por contrato. Anduvo pensando en esos desvíos mientras caminaba -quizá por última vez- por las calles polvorientas del pueblo", escribe Piglia (2010: 284-285). 
La filosofía y la novela policiaca no están sincronizadas. Cuando a la filosofía le llegan las dudas en torno al método analítico, a la imposición de un sistema robusto, surge con fuerza este género que se sostiene precisamente en la confianza en la deducción lógica, capaz de reconstruir cualquier crimen. Como si le anduviera a la zaga, más ingenua, o solo preocupada por las formas exquisitas del juego. Pero Piglia, al hacer de la investigación de su comisario algo rudimentario, poco profesional, más intuitivo que racional, hace con la novela policiaca lo que Cervantes hace con la novela de caballería: Replantearla desde dentro, cuestionando su propio mecanismo, hasta hacerla colapsar. Hasta hacer de ella otra cosa. Esa ficción paranoica. Colocándola en un nivel superior, que hace del inmediatamente inferior su objeto de estudio: propiamente metaliteratura, sobre las claves de acceso y el encadenamiento de los pensamientos, dentro, pero también fuera, de la novela. Con una investigación que, con la horma de la novela policiaca, merodea la hermenéutica, una teoría para la interpretación más flexible, más liberada, equidistante del univocismo y el relativismo más extremos. Porque cuando parece que Croce está abocado a la equivocidad, a la ausencia total de un método, con solo la asociación libre, sin el recurso siquiera de la frónesis, cuando el lector se ha hecho a la idea de que las intuiciones de Croce no tienen ningún agarradero, este le argumenta a Renzi el uso de la analogía: el conocimiento no es el desvelamiento, sino una relación, le dice. Más inestable que la argumentación lógica de otros detectives. Como si supiera que esos agarraderos son solo alfileres, no los amarres firmen que cree tener el que pretende una interpretación unívoca. Lo mismo que escribe el narrador de Cosmos: "Era una analogía, débil, fantástica, pero hay que recordar que estaba en juego esa misma «relación» que tendía a conformar un orden determinado" (Gombrowicz 1982: 44). Aunque Croce sin caer en el relativismo exasperante de Leon, en su desconfianza por hacerse con la realidad: "De todos modos la realidad circundante se hallaba ya contagiada por la posibilidad de distintos significados y esto me separaba, me aislaba de todo", dice en Cosmos (Gombrowicz 1982: 46), muy lejos del comisario de Piglia, por esa actitud derrotista al final. Aunque uno y otro pretenden lo mismo: crear un sentido para conformar la realidad; y del mismo modo, con series, con encadenamientos, que lo vinculen todo -casi hasta llegar al rizoma de Deleuze y Guattari, con la conexión de cualquier punto con otro punto cualquiera (1994: 25)-. Que en el plano metaliterario remite a la lectura: como acto de construcción de un sentido para el texto: quizá el principal interés teórico de Piglia. Escribe el argentino: "El lector entendido como descifrador, como intérprete, ha sido muchas veces una sinécdoque o una alegoría del intelectual. [...] Como alguien que se enfrenta con el mundo en una relación que en principio está mediada por un tipo específico de saber. La lectura funciona como un modelo general de construcción del sentido. La indecisión del intelectual es siempre la incertidumbre de la interpretación, de las múltiples posibilidades de la lectura" (Piglia 2005: 103). Lo que quiso Gombrowicz con su Cosmos: "una novela sobre la formación de la realidad", dijo de ella: un ejercicio de hermenéutica, de 
construcción o reconstrucción de la realidad que, en su término medio, buscaría, como ha escrito Beuchot, determinar o delimitar la interpretación sin cerrarla.

Blanco nocturno es, con esta perspectiva, una búsqueda del equilibrio, un lugar con el que hacer frente a una crisis epistémica que se le muestra rotunda, contundente, amenazante: Primero el desequilibrio: el desengaño con el método de la resolución policial del crimen, que le lleva a Croce a romper amarras con la argumentación lógica, de conjunción de evidencias, más atento a sus intuiciones. Con la traslación a la hermenéutica: la caída en el equivocismo, al huir del univocismo. Y luego el reequilibrio: la metáfora, la analogía, algunas de esas intuiciones más bien como símbolos (Cf. Beuchot 2008: 143-144), como otro modo de sutura más honesto con el propio mecanismo del pensamiento. ${ }^{8}$ Más cerca de la metonimia de lo que Piglia piensa: de la metonimia por atribución, al darle el comisario Croce una interpretación a las causas del suceso, al aplicar hechos y cualidades a los sospechosos para resolver, por otro camino, el caso: Con la atribución, esta cualidad metonímica, como un nuevo punto de encuentro entre las novelas de detectives y la hermenéutica.

\section{BIBLIOGRAFÍA}

Álvarez Colín, Luis.

2004 "La hermenéutica analógica: Aportación fundamental de la filosofía mexicana", Contrastes, vol. IX, pp. 5-26.

BOLAÑO, Roberto.

2003a El gaucho insufrible. Barcelona: Anagrama.

2003b Los detectives salvajes. Barcelona: Anagrama.

2004 2666. Barcelona: Anagrama.

2008 Entre paréntesis. Barcelona: Anagrama.

2011 Los sinsabores del verdadero policía. Barcelona: Anagrama.

BORGES, Jorge Luis.

2008 "El arte narrativo y la magia", en Obras completas I. Buenos Aires: Emecé.

DeLeuze, Gilles y Félix GuATTARI.

1994 Mil mesetas. Capitalismo y esquizofrenia. Valencia: Pre-textos.

${ }^{8}$ Lo que proponen Deleuze y Guattari: "El pensamiento no es arborescente, el cerebro no es una materia enraizada ni ramificada [sino] un sistema aleatorio de probabilidades." (1994: 20) 
ECHABURU SOLER, Sergi.

2006 Los héroes de la novela policiaca. Barcelona: Grafein Ediciones.

ECO, Umberto.

1984 Obra abierta. Barcelona: Planeta.

FERRARI, Enrique.

2011 "De la autonomía del arte y la epistemología: Sobre héroes y tumbas como marco de un «Informe sobre ciegos» metaliterario", Thémata, $\mathrm{n}^{\circ} 44$, pp. 290-300.

FORSTER, E.M.

1990 Aspectos de la novela. Madrid: Debate.

GADAMER, Hans-Georg.

2001 Verdad y método. Salamanca: Sígueme.

GomBrowicz, Witold.

1982 Cosmos. Barcelona: Seix Barral.

HEGEL, Georg Wilhelm Friedrich.

1993 Fundamentos de la filosofía del derecho. Madrid: LibertariasProdhufi.

LLEDÓ, Emilio.

1990 El silencio de la escritura. Madrid: Espasa Calpe.

MARGOLIS, Joseph.

1999 What, After All, Is a Work of Art? Pennsylvania: The Pennsylvania State University Press.

PIGLIA, Ricardo.

2000 Formas breves. Barcelona: Anagrama.

2005 El último lector. Barcelona: Anagrama.

2010 Blanco nocturno. Barcelona: Anagrama.

SÁBATO, Ernesto.

1999 Sobre héroes y tumbas. Barcelona: Seix-Barral.

ZAMBRANO, María.

2000 Hacia un saber sobre el alma. Madrid: Alianza. 